\title{
White Pine Blister Rust Resistance in Limber Pine: Evidence for a Major Gene
}

\author{
A. W. Schoettle, R. A. Sniezko, A. Kegley, and K. S. Burns
}

First author: United States Department of Agriculture (USDA), Forest Service, Rocky Mountain Research Station, Fort Collins, CO 80526; second and third authors: USDA Forest Service, Dorena Genetic Resource Center, Cottage Grove, OR 97424; and fourth author: USDA Forest Service, Forest Health Protection, Golden, CO 80401.

Accepted for publication 2 August 2013.

\begin{abstract}
Schoettle, A. W., Sniezko, R. A., Kegley, A., and Burns, K. S. 2014. White pine blister rust resistance in limber pine: Evidence for a major gene. Phytopathology 104:163-173.

Limber pine (Pinus flexilis) is being threatened by the lethal disease white pine blister rust caused by the non-native pathogen Cronartium ribicola. The types and frequencies of genetic resistance to the rust will likely determine the potential success of restoration or proactive measures. These first extensive inoculation trials using individual tree seed collections from $>100$ limber pine trees confirm that genetic segregation of a stem symptom-free trait to blister rust is consistent with inheritance by a

single dominant resistance $(R)$ gene, and the resistance allele appears to be distinct from the $R$ allele in western white pine. Following previous conventions, we are naming the $R$ gene for limber pine " $\mathrm{Cr} 4$." The frequency of the $\mathrm{Cr} 4$ allele across healthy and recently invaded populations in the Southern Rocky Mountains was unexpectedly high (5.0\%, ranging from 0 to $13.9 \%$ ). $\mathrm{Cr} 4$ is in equilibrium, suggesting that it is not a product of a recent mutation and may have other adaptive significance within the species, possibly related to other abiotic or biotic stress factors. The identification of $\mathrm{Cr} 4$ in native populations of limber pine early in the invasion progress in this region provides useful information for predicting near-term impacts and structuring long-term management strategies.
\end{abstract}

Pest and pathogen introductions into managed and wild ecosystems can be devastating to host populations and ecosystem function. An example is the impact resulting from the introduction of Cronartium ribicola J. C. Fisch., the nonnative fungal pathogen that causes the lethal disease white pine blister rust (WPBR), into North America in the early 1900s. This disease has heavily affected the commercial eastern white pine (Pinus strobus), western white pine (P. monticola), and sugar pine (P. lambertiana) industries. The pathogen continues to spread and affect other keystone fiveneedle white pine species in mountain-top ecosystems throughout western North America. The upper subalpine and treeline ecosystems are ecologically valuable to landscape dynamics, watershed protection, and biodiversity, and maintaining their health is important for ecological sustainability and to society $(23,52)$.

Concerns about the high-elevation white pine species and ecosystems have led to increased investigation of what levels and types of genetic resistance to WPBR might be present in these species $(27,46)$. Limber pine (P. flexilis) is one of the nine North American white pine species, all of which are highly susceptible to WPBR. Limber pine is a long-lived tree species that inhabits diverse ecosystems throughout the Rocky Mountains and the Great Basin, and west to the Sierra Nevada Mountains and southern California. In the Southern Rockies, limber pine has a very broad elevational range and defines both the grassland and alpine tree lines (1,600 and 3,400 $\mathrm{m}$ in elevation, respectively) (43). It is often the only tree species that can occupy steep, windswept headwater habitats and plays a key role in snow capture,

Corresponding author: A. W. Schoettle; E-mail address: aschoettle@fs.fed.us

* The $e$-Xtra logo stands for "electronic extra" and indicates that Figures 2 and 4 appear in color online.

http://dx.doi.org/10.1094/PHYTO-04-13-0092-R

This article is in the public domain and not copyrightable. It may be freely reprinted with customary crediting of the source. The American Phytopathological Society, 2014 mediating snow melt, and controlling erosion (40). On more mesic sites, as an early serial species, it facilitates the establishment of other conifer species and succession $(11,38)$. Limber pine's large, nearly wingless seeds provide diet for birds, squirrels, rodents, and bears. The loss of limber pine from the Southern Rockies would affect ecosystem functions and biodiversity across the mountain landscapes (40).

As a result of the combined threats of WPBR, expanding bark beetle pressure, and climate change in mountain environments, limber pine was recommended (10) and approved for endangered species status under The Wildlife Act in Alberta (Canada) (14). In the United States, active conservation efforts in the Southern Rocky Mountains are underway $(5,41)$. Impacts of WPBR are evident in the northern populations; the pathogen is still spreading and many southern populations are threatened but not yet invaded $(5,20)$. The types of genetic resistance and their frequencies will likely influence the fate of limber pine in the most affected ecosystems as well as the potential success of restoration or proactive management of ecosystems likely to be invaded (44). Gathering baseline information on resistance to WPBR in threatened populations before they are heavily affected supports additional management opportunities to sustain populations and genetic diversity and mitigate the development of impacts over time (44).

Past multispecies comparisons of WPBR resistance confirmed that limber pine is highly susceptible to WPBR but that some resistance is expressed in field conditions and artificial inoculation trials $(1,2,6,9,16,17,30,47,48,50)$. Most of these studies included fewer than five limber pine seed lots. However, Delatour and Birot (9) included 17 limber pine seed lots, for which the inoculation results revealed wide variation in susceptibility of 0 to $100 \%$. Unfortunately, the source, composition, and results for each lot were not reported. More extensive studies to investigate genetic variation in resistance within limber pine have been lacking.

Though rare in tree species (37), major genes for resistance have been identified in the white pine-WPBR pathosystem in 
sugar pine ( $P$. lambertiana; $C r l)$, western white pine ( $P$. monticola; $\mathrm{Cr} 2$ ), and southwestern white pine (P. strobiformis; $C r 3)$ (30-33). The resistance $(R)$ alleles are hypothesized to mediate a hypersensitive reaction (HR) in the needles, resulting in a distinctive infection lesion (spot with a necrotic circumference) and the absence of stem cankers, unless the tree is challenged by a virulent strain of the pathogen. Kinloch and Dupper (30) reported the appearance of the distinctive HR lesions on needles of young limber pine seedlings from one bulk seed lot from Colorado after artificial inoculation with $C$. ribicola. Because a bulked seed lot of unknown composition was used in the Kinloch and Dupper (30) trial, they were unable to test for segregation of the apparent HR trait to assess its consistency with inheritance via a major gene.

The objective of this report is to provide the first investigation of family variation for resistance to WPBR in limber pine, with focus on complete resistance (i.e., HR or canker-free seedlings) and its frequency. Specifically we (i) describe the phenotypic resistance response of young limber pine seedlings following artificial inoculation with C. ribicola, (ii) assess whether an HRtype resistance phenotype of limber pine is a family trait that segregates consistent with inheritance by a single dominant resistance $(R)$ gene, (iii) test whether the $R$ allele in limber pine is different from $C r 2$ in western white pine, and (iv) estimate the frequency of the $R$ allele in healthy and recently invaded populations from the Southern Rocky Mountains.

\section{MATERIALS AND METHODS}

A series of artificial inoculation tests were conducted at Dorena Genetic Resource Center (Cottage Grove, OR); we focus here on aspects of two inoculation tests in particular (trials 06-06 and 0707) with supplemental information provided from other tests (trials 06-07, 07-08a, and 07-08b) (Table 1). We tested openpollinated progenies from individual seed trees from 12 naturally established stands throughout the Southern Rocky Mountains from southern Wyoming to southern Colorado. In all, 3 to 16 individual trees were sampled from each population (average of 9). In subsequent articles, we will address the geographic variation in complete disease resistance among populations as well as other resistance types. Seed were collected in 2003, 2005, and 2006; seed trees were tagged and geo-referenced. To help minimize relatedness among progenies, sampled trees were located a minimum of $200 \mathrm{~m}$ apart from one another. To reduce the probability of collecting self-pollinated seed, cones were collected from the upper third or half of the crown. WPBR presence was evident (i.e., cankered trees) in some populations at the time of sampling (six stands) and not in others (six stands). Some of the infected sites had been challenged by WPBR for 10 to 15 years at the time of sampling and others for only a few years $(3,4,22)$. Mortality of mature, reproductive trees by rust was not common and rust incidence was 11 to $80 \%$ among the six invaded sites. For those populations for which $C$. ribicola was present, seed from both cankered and canker-free trees were sampled; parent tree phenotypes were reconfirmed in the spring of the following and subsequent years, when aecia were visible. No change in infection status of parent trees has been noted in subsequent visits. For the six populations that had no evidence of disease, trees were not selected for any phenotype other than being healthy and cone-bearing. Seed were extracted by hand and stored at $-18^{\circ} \mathrm{C}$.

In addition, seedlings from previously tested families of western white pine and sugar pine with known phenotypes were included in each replicate of the young seedling tests in each inoculation year as bioindicators of inoculation success. Known families from trial 06-06 were included to test repeatability of results under different growth and environmental conditions and sources of inocula in the older seedling inoculation trials (07-08a and $b$ ).

Trial 06-06 (2006 seedling culture and inoculation). Seed from 90 seed trees were stratified for 60 days at $2^{\circ} \mathrm{C}$ and directly sown into Ray Leach cone-tainers $\left(164 \mathrm{~cm}^{3}\right.$; Stewe and Sons, Tangent, OR) on 6 July 2006 in an unheated, open-air, plasticcovered greenhouse at Dorena Genetic Resource Center (DGRC), Cottage Grove, OR. A randomized complete block design was utilized. Row plots of seven tubes per family, some with multiple germinants from each family, were randomly assigned to each of three blocks ( $n=21$ tubes per family). An additional block was constructed of seedlings to serve as uninoculated controls. All of these young seedlings had cotyledons and primary needles at inoculation; some also had a few secondary needles. Seedlings were transferred into the inoculation chamber and held for 2 days at $16.7^{\circ} \mathrm{C}$ and $100 \%$ relative humidity $(\mathrm{RH})$ until inoculation on 21 September 2006. Each block was inoculated in a separate tent following the DGRC protocols (39). C. ribicola-infected Ribes hudsonianum var. petiolare leaves from four eastern Oregon areas on the Wallowa-Whitman and Umatilla National Forests near whitebark pine (P. albicaulis) populations were used in the inoculation. C. ribicola in eastern Oregon is considered a wild type because it has little or no known virulence ( $v c r 2$ or $v c r l)$ to the major gene for the HR response in western white pine $(\mathrm{Cr} 2)$ or sugar pine $(C r l)$ (34). The infected Ribes leaves were placed on screens above the pine seedlings and spore drop was monitored; Ribes leaves were removed once the target spore density was reached (typically after $<15 \mathrm{~h}$ ). Target spore density was 10,000 spores $\mathrm{cm}^{-2}$ and actual inoculation spore density average was 10,010 spores $\mathrm{cm}^{-2}$ (range: 8,680 to 12,180 spores $\mathrm{cm}^{-2}$ ), with an average basidiospore germination (assessed on agar plates) of $99.1 \%$.

Beginning at 2 months postinoculation, infection and disease traits (see below) were recorded and tracked for each seedling at 13 inspections over the following 24 months. At $\approx 4$ months after the 2006 inoculation (mid-January), mice severely damaged 327 seedlings, reducing the sample sizes for some families to $<10$ seedlings. These families were excluded from analysis, and some of the families were resown in trial 07-07. In all, 77 of the original 90 families were available for analyses and are reported here.

Trial 06-07 (2006 seedling culture and 2007 inoculation). To characterize symptoms on older seedlings with secondary needles, seedlings from 10 families that were sown in 2006 were inoculated for the first time on 19 September 2007 (trial 06-07). Inoculation spore density averaged 9,753 spores $\mathrm{cm}^{-2}$ (range: 8,740 to 10,960 spores $\mathrm{cm}^{-2}$ ). The trial 06-07 results were not used in the analyses to infer seed tree genotype, trait segregation,

TABLE 1. Summary of Cronartium ribicola inoculation trials for limber pine reported here ${ }^{\mathrm{a}}$

\begin{tabular}{|c|c|c|c|c|c|c|}
\hline Trial name & $\begin{array}{c}\text { Number of } \\
\text { families }\end{array}$ & Sow date & Inoculation date & Inoculum source & $\begin{array}{l}\text { Preinoculation } \\
\text { plant culture }\end{array}$ & $\begin{array}{l}\text { Postinoculation } \\
\text { plant culture }\end{array}$ \\
\hline $06-06$ & 77 & June 2006 & September 2006 & Wild type (avcr 1, avcr2) & Pots in $\mathrm{GH}$ & Pots in $\mathrm{GH}$ then outside \\
\hline 06-07 & 10 & June 2006 & September 2007 & Wild type (avcr 1, avcr 2$)$ & Pots in GH & Pots in $\mathrm{GH}$ then outside \\
\hline 07-07 & 35 & April 2007 & September 2007 & Wild type (avcr 1, avcr 2$)$ & Pots in GH & Pots in $\mathrm{GH}$ then outside \\
\hline 07-08a & 74 & April 2007 & October 2008 & Wild type (avcr 1, avcr 2$)$ & Pots in $\mathrm{GH}$ & Frames outside \\
\hline $07-08 b$ & 72 & April 2007 & September 2008 & Wild type + Champion Mine (avcr 1, avcr $2, v c r 2)$ & Pots in $\mathrm{GH}$ & Frames outside \\
\hline
\end{tabular}

a See text for description of the bulked inoculum sources. The greenhouse (GH) was unheated, with open-air sides and a plastic cover. 
or gene frequencies but provided observational data on secondary needle phenotypes following artificial inoculation. Seedling numbers per family varied from five to seven.

Trial 07-07 (2007 seedling culture and inoculation). Seed from 35 seed trees ( 7 of them repeated from the 2006 trial) were sown and inoculated in 2007. To have larger seedlings at inoculation than in trial 06-06, seedlings were stratified and sown earlier ( 2 April compared with 6 July, respectively). Rather than direct sowing, seed were germinated in plastic boxes in a growth chamber $\left(25^{\circ} \mathrm{C}, 100 \% \mathrm{RH}\right)$; upon radicle emergence, seedlings were transplanted into the Ray Leach cone-tainers $\left(164 \mathrm{~cm}^{3}\right)$ and moved to the greenhouse; germination and transplantation continued until the desired sample size was reached (15 to 20 days). A randomized complete block design was utilized; row plots of 12 seedlings per family were randomly assigned to each of three blocks ( $n=36$ seedlings per family). Due to uneven germination, sample size varied from 12 to 36 seedlings among the families. Plant culture in the greenhouse was the same as in 2006. All of these young seedlings had cotyledons and primary needles at inoculation; some also had a few secondary needles. Inoculation occurred on 19 September 2007 with a final average spore density of 9,753 spores $\mathrm{cm}^{-2}$ (range: 8,740 to 10,960 spores $\mathrm{cm}^{-2}$ ). Ten disease symptom inspections were conducted over the following 24 months. Known susceptible check seed lots of western white pine were included as in 2006.

Trials 07-08a and 07-08b (2007 seedling culture and 2008 inoculation). This fourth study included 74 families sown in 2007 , cultured in the greenhouse for two growing seasons, inoculated in fall 2008, and transplanted into large frames and grown outside at DGRC (trial 07-08a and b). Trial 07-08 is ongoing and its objective is to quantify and describe partial resistance as well as complete resistance in limber pine and to test against two sources of inoculum. Results presented here will be limited to those families that were previously tested in trials 06-06 and 0707; the results of the full study will be presented elsewhere. The seedlings in trial 07-08 were subdivided into two subtrials (trials 07-08a and 07-08b): one set of seedlings (trial 07-08a) were inoculated with wild-type inoculum from the same sources as in the trials 06-06, 06-07, and 07-07 and the other set of seedlings (trial 07-08b) were inoculated with $C$. ribicola from geographic sources near the Champion Mine area and the DGRC's Ribes garden (Cottage Grove Ranger District, Umpqua National Forest, OR) that are naturally infected by local $C$. ribicola that contains a high frequency of virulent $v c r 2$ genotypes (34) that can overcome $\mathrm{Cr} 2$ resistance in western white pine (Table 1). A randomized complete block design was utilized for each subtrial; row plots of eight seedlings per family were randomly assigned to each of four blocks for each trial $07-08 \mathrm{a}$ and $07-08 \mathrm{~b}(n=32$ per family per inoculation). Inoculation occurred on 9 October 2008 for trial 07-08a and 17 September 2008 for trial 07-08b, and final average spore density was 3,841 and 6,120 spores $\mathrm{cm}^{-2}$, respectively. Three disease inspections were conducted over the following 24 months and further assessments to examine partial resistance traits have been made and are ongoing. Some families shown to be susceptible and to have complete resistance in trials 06-06 and 07-07 were included to test repeatability under different growth and environmental conditions and the two inoculum sources in the 2008 inoculations.

Infection and disease traits assessed at each inspection. At each inspection for all trials, every seedling was assessed and followed for a core set of traits, including WPBR stem symptoms (SSs), mortality by WPBR, mortality by other causes (if known, it was recorded), and overall seedling vigor; in the early assessments of all trials (i.e., first 12 months after inoculations) presence or absence of needle spots (lesions) was also recorded. In addition, for the 2006 and 2007 inoculations, early inspections also included assessment of each seedling for needle spot types (all susceptible, some HR-type [with necrotic border], question- able necrotic type, or all HR-type), spot size (normal, small, or both), spot number (none, $<10$, or $>10$ ), and spot colors. In addition to the core traits, later inspections recorded presence or absence of aecia, spermatia, and necrotic (and abscising) needles. In addition, for trial 06-06, a subjective assessment of stem stiffness (similar stiffness, slightly stiffer, and much stiffer than the uninoculated seedlings) was conducted for each seedling.

Testing segregation ratios. To test for segregation ratios of the SS-free to SS traits within families, $\chi^{2}$ tests were run.

Zygotic and gametic frequencies of the $\boldsymbol{R}$ allele. Assuming a single dominant allele, the zygotic $(\mathrm{Z})$ and gametic $(\mathrm{G})$ frequencies of the $R$ allele ( $\mathrm{Cr} 4$ ) were calculated according to Kinloch et al. (34). The $\mathrm{Z}$ frequency of $\mathrm{Cr} 4$ in any population is the number of heterozygotes observed divided by twice the number of seed trees evaluated. The $\mathrm{G}$ frequency is assessed by estimating the incidence $\mathrm{Cr} 4$ in the ambient pollen cloud; the SS-free seedlings in families from nonsegregating, susceptible (cr4cr4) seed trees are assumed to have derived their resistance from unknown $\mathrm{Cr} 4$ pollen donors. Therefore, to calculate $\mathrm{G}$, these $\mathrm{Cr} 4$ pollen receptors were counted, divided by the total number of symptomatic seedlings from that seed tree, and averaged over all such seed trees from each population. The nonsegregating families used in the calculation of $\mathrm{G}$ were those that did not fit the segregation ratios of SS-free/SS seedlings of 3:1, 1:1, or 1:0.

Testing for Hardy-Weinberg equilibrium. For trials 06-06 and 07-07, the observed number of seed trees, inferred from the segregation ratios of SS-free/SS progeny, designated as homozygous dominant $(\mathrm{Cr} 4 \mathrm{Cr} 4)$, heterozygous $(\mathrm{Cr} 4 \mathrm{cr} 4)$, and homozygous recessive (cr4cr4) genotypes, was 1,14 , and 90 , respectively. The recessive allele frequency $(q)$ was calculated as the sum of double the number of homozygous recessive seed trees plus the number of heterozygous seed trees divided by the total number of alleles (105 seed trees $\times 2$ alleles). The dominant allele frequency $(p)$ was calculated as $1-q$. The expected next-generation distribution of genotypes $\mathrm{Cr} 4 \mathrm{Cr} 4, \mathrm{Cr} 4 \mathrm{cr} 4$, and $\mathrm{cr} 4 \mathrm{cr} 4$ were calculated as $p^{2}, 2 p q$, and $q^{2}$, respectively, for 105 individuals. A $\chi^{2}$ test was used to test whether the observed genotype distribution significantly deviated from the expectations of the Hardy-Weinberg equilibrium.

\section{RESULTS}

Inoculation efficacy. The inoculations successfully infected young limber pine seedlings with $C$. ribicola (Table 2). All but 6 of the 2,079 exposed seedlings $(0.3 \%)$ in trial $06-06$ and 3 of the 987 exposed seedlings $(0.3 \%)$ in the trial $07-07$ inoculation showed the characteristic needle spots (lesions) caused by successful fungal colonization within the first 3 months after inoculation. Most of the seedlings had dozens or more needle spots. In trial 06-06, two of the spot-free seedlings later developed WPBR SSs; only four seedlings (each from a different family) never developed any disease symptoms and may have escaped infection ( $0.2 \%$ escapes). Each of the three seedlings in the 2007 inoculation for which spots were not detected developed disease SSs. The percentage of suspected escapes in the inoculation of 18-monthold seedlings in 2008 was also very low (Table 2). In all cases, the spot-free seedlings were in different families and showed no

TABLE 2. Efficacy of inoculations to infect limber pine seedlings in four trials

\begin{tabular}{lcccc}
\hline $\begin{array}{l}\text { Trial } \\
\text { name }\end{array}$ & $\begin{array}{c}\text { Total } \\
\text { number } \\
\text { of } \\
\text { seedlings }\end{array}$ & $\begin{array}{c}\text { Number of } \\
\text { seedlings } \\
\text { without } \\
\text { spots }\end{array}$ & $\begin{array}{c}\text { Number } \\
\text { of seedlings } \\
\text { without spots or } \\
\text { stem symptoms }\end{array}$ & $\begin{array}{c}\text { Seedlings } \\
\text { without spots } \\
\text { or stem } \\
\text { symptoms }(\%)\end{array}$ \\
\hline $06-06$ & 2,079 & 6 & 4 & 0.2 \\
$07-07$ & 987 & 3 & 0 & 0.0 \\
$07-08 \mathrm{a}$ & 2,353 & 5 & 3 & 0.1 \\
$07-08 \mathrm{~b}$ & 2,095 & 1 & 0 & 0.0 \\
\hline
\end{tabular}


pattern. In these studies, we cannot discern whether these spotfree seedlings randomly escaped infection or are expressing a resistance that prevents infection (19). In each trial, all seedlings from the known susceptible families of western white pine and sugar pine developed needle spots, WPBR SSs, and subsequently died over the 24-month assessment period, providing further evidence of effective inoculations. As expected, the western white pine families previously shown to carry the $C r 2$ gene that were inoculated with trial 07-08a and b (with vcr2) segregated for disease symptoms (26) or were fully susceptible, respectively.

Seedling mortality by unknown causes was low (trial 06-06: 35 of 2,079 seedlings, 2\%; trial 07-07: 19 of 987 seedlings, $2 \%$; trial 07-08a: 4 of 2,353 seedlings, $0.2 \%$; and trial $07-08 \mathrm{~b}$ ver $2: 8$ of 2,095 seedlings, $0.4 \%$ ). This mortality by unknown factors was distributed among families; therefore, not affecting sample sizes disproportionately for any one family.

Time course of disease symptom development for greenhouse trials. Infection spots (lesions) on cotyledons and needles were evident within 2 months of inoculation and continued to develop over the next several months. Early SSs, characterized by swollen stem tissue often with orange coloration showing through the thin bark at the base of the infected needle, were observed as early as 3 months after inoculation for some seedlings. SSs were evident on most susceptible seedlings 6 to 10 months after inoculation (Fig. 1) and developed into bulbous swellings of the stem and the base of fascicles; the fungus also spread into the new growth. C. ribicola spermatia were observed on numerous SS seedlings 8 months after inoculation (late May) in the 2006 inoculation and slightly earlier for the seedlings inoculated in 2007. Mortality attributed to WPBR began at 9 months postinoculation and continued over the following 15 months (Fig. 1). Aecia were observed on SS seedlings $\approx 18$ months after inoculation in all trials.

Distribution of other traits. The number and color of infection spots per seedling did not predict disease development. In trial 06-06, $49 \%$ of seedlings that later developed SS and $60 \%$ of those that remained SS-free had $>10$ spots per seedling several months following inoculation. In the early months after inoculation, one or more spot colors were seen on the same seedling, including yellow (present on $84 \%$ of the seedlings), orange $(13 \%)$, red $(24 \%)$, magenta $(28 \%)$, and pink $(<1 \%)$; the greenisland spot type was also evident on some secondary needles. The diversity of infection reactions in limber pine may be a con-

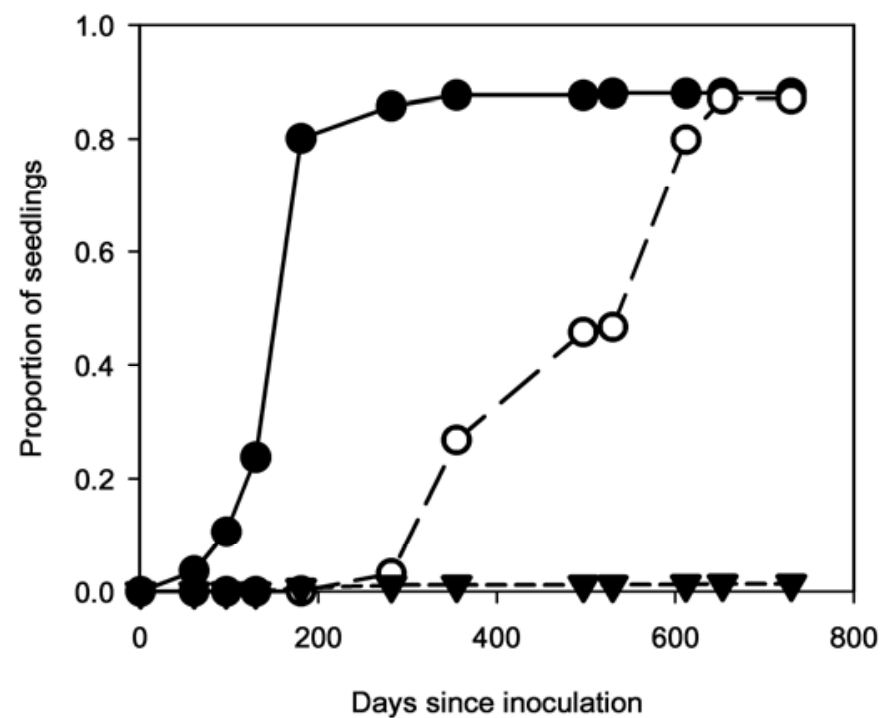

Fig. 1. Time course of stem symptom development and mortality for young limber pine seedlings inoculated with Cronartium ribicola in trial 06-06. The proportion of seedlings with white pine blister rust (WPBR) stem symptoms (solid circles), that died from WPBR (open circles), and died from unknown causes (solid triangles) over the course of the trial are plotted. sequence of variation within the inoculation population of $C$. ribicola because these tests were not conducted with single-spore isolates. However, the colors of the infection reactions were more diverse for limber pine than other species tested under similar protocols at DGRC, where the predominant needle spot color is yellow for western white pine, sugar pine, and southwestern white pine and almost exclusively so for whitebark pine (R. Sniezko, unpublished data).

In greenhouse studies, evidence of the hypersensitive-like needle spot (HR-type spot) is usually observed within 4 to 8 months of inoculation for young seedlings of some families of western white pine, sugar pine, and southwestern white pine and in a bulk lot of limber pine (30). The HR needle spot type was not clearly observed in the young limber pine seedling families inoculated here and was recorded on $<1 \%$ of the seedlings, and not all of these remained SS-free. In all, $88 \%$ of seedlings that later developed SS and 53\% of those that remained SS-free had susceptible-type spots 3 months following inoculation. Spots on the remaining seedlings at that time were characterized as "questionable" because they were not spreading like a susceptible spot yet lacked any necrotic ring typical of HR spots in other white pine species. By 6 months postinoculation, the spots on $74 \%$ of the limber pine seedlings that remained SS-free appeared as defined, discrete, and brown compared with the normal spreading yellow susceptible spots on cotyledons and primary and secondary needles (Fig. 2). However, this spot type was not always diagnostic of resistance because $20 \%$ of seedlings with spots of this type 6 months postinoculation later developed cankers. HR-type spots with the necrotic margin and green island spots were observed on secondary needles of some of the older limber pine seedlings inoculated in 2007 and 2008 that remained SS-free.

Ten months after the 2006 inoculation, a greater proportion of primary needles were necrotic for SS-free seedlings compared with SS seedlings (Figs. 3 and 4). The infected (spotted) needles on SS-free seedlings were those that prematurely became necrotic. In addition to the timing of needle death, the course of primary needle death proceeded differently for inoculated SS-free versus SS seedlings; on SS-free seedlings, needle necrosis began at the base of the needle near the abscission zone, whereas infected primary needles on SS seedlings tended to develop chlorosis at the needle tip that progressed proximally over the following months. Compared with natural needle necrosis on the uninoculated seedlings of the same families, the process of needle necrosis of infected needles for SS-free seedlings was similar but accelerated by 6 to 8 months (data not presented). Necrotic primary needles of both SS-free and uninoculated seedlings were retained on the seedlings but would easily detach at a clean abscission zone if lightly pulled. The pattern of needle blanching and necrosis among SS-free seedlings was even more obvious for secondary needles of the seedlings sown in 2006 and inoculated in 2007 and was followed by rapid shed of the individual infected secondary needles (Fig. 4). As a consequence of needle necrosis, blanching, or abscission, SS-free seedlings showed reduced spotting over time; in trial 06-06, 12 months after inoculation, only $9 \%$ of the seedlings that remained SS-free had any live needles with spots, compared with $89 \%$ of the SS seedlings (Table 3).

Shoot extension growth occurred the spring following inoculation for some of the seedlings with SS. In contrast, most seedlings that remained SS-free grew normally and were morphologically similar to uninoculated seedlings (except for early leaf necrosis and abscission); some even produced lammas growth. Stem stiffness, assessed 12 months after inoculation in trial 06-06, also varied among seedlings; $89 \%$ of seedlings with SS tended to have thicker and stiffer stems, even before aecia production, than those that had no other signs of disease. However, $17 \%$ of seedlings that remained disease-free throughout the study were noticeably stiffer 
than other SS-free seedlings and the uninoculated seedlings of the same family.

Family variation in frequency of SS-free trait. There was wide variation among the 105 families in the proportion of SSfree seedlings ( 0.0 to 0.91 ) in trials 06-06 and 07-07 (Table 4; Fig. $5)$. If the SS-free trait in limber pine is a single resistance trait controlled by a single dominant $R$ gene, similar to $\mathrm{Cr} 1, \mathrm{Cr} 2$, and $\mathrm{Cr} 3$ in the other white pine species, and there are no other resistances or factors to modify $R$ gene expression in these families, Mendelian segregation of the SS-free trait within a family would be expected to fit the ratio 1:1 (SS-free/SS) if the seed tree was heterozygous for an $R$ allele and the pollen sources were homozygous recessive. If the frequency of the $R$ allele is high in the population and, therefore, in the pollen cloud, or if mating is not random or includes a fair amount of selfing, a segregation ratio $>1: 1$ and approaching 3:1 SS-free/SS within a family may be observed. Therefore, parental genotypes can be inferred from progeny performance (33). In trials $06-06$ and $07-07,15$ of the 105 (14.3\% of the seed parents) families tested fit the expected segregation ratios that would suggest control by a single dominant gene; 14 fit the expected ratio of 1:1 (denoting a heterozygote) and 4 of these also fit the 3:1 expected ratio (Table 3 ). The segregation ratio of 1:0 (91\% SS-free) of one family (family 58) suggests that the seed tree may be homozygous for the resistance $R$ allele yet there may have been some incomplete expression of resistance in the progeny. In all, 28 of 105 families fit a 1:3 ratio (and only three of these also fit 1:1 ratio) and tended to be at sites where other seed trees with $1: 1$ or $3: 1$ segregation ratios were detected (data not shown).

For those families tested in both 2006 and 2007, segregation of progeny was consistent among trials (Table 5). The segregation ratios were also similar for seedling families inoculated in 2008 at 18 months of age under inoculation with the wild-type source of C. ribicola as well as from geographic sources of $C$. ribicola that contain the virulent strain $(v c r 2)$ that overcomes $C r 2$ in western white pine (Table 5).
Across both the 2006 and 2007 inoculation trials, all of the families that segregated for the SS-free trait with $1: 1$ and $3: 1$ ratios (SS-free/SS) were from phenotypically disease-free seed trees in the field; some were in stands that have not yet been challenged by WPBR. The overall $\mathrm{Z}$ and $\mathrm{G}$ frequencies of the $R$ allele were 0.07143 and 0.05012 , respectively (Table 6). Field sampling for disease-free seed trees in populations invaded by WPBR resulted in a higher $\mathrm{Z}$ frequency than for seed trees that were randomly sampled from populations not yet invaded by the rust (therefore, with no field selection phenotype related to

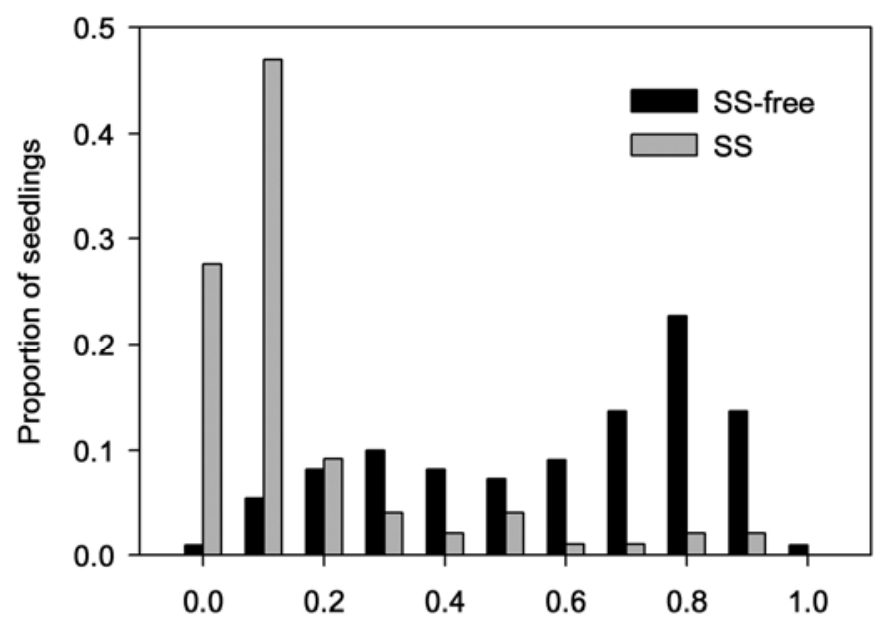

Proportion of primary needles necrotic per seedling

Fig. 3. Proportion of primary needles that were necrotic on each assessed seedling 10 months postinoculation (trial 06-06). In all, 220 seedlings were assessed, of which 110 developed white pine blister rust stem symptoms (light bars) and 110 remained stem-symptom (SS)-free (dark bars) for the duration of the study.

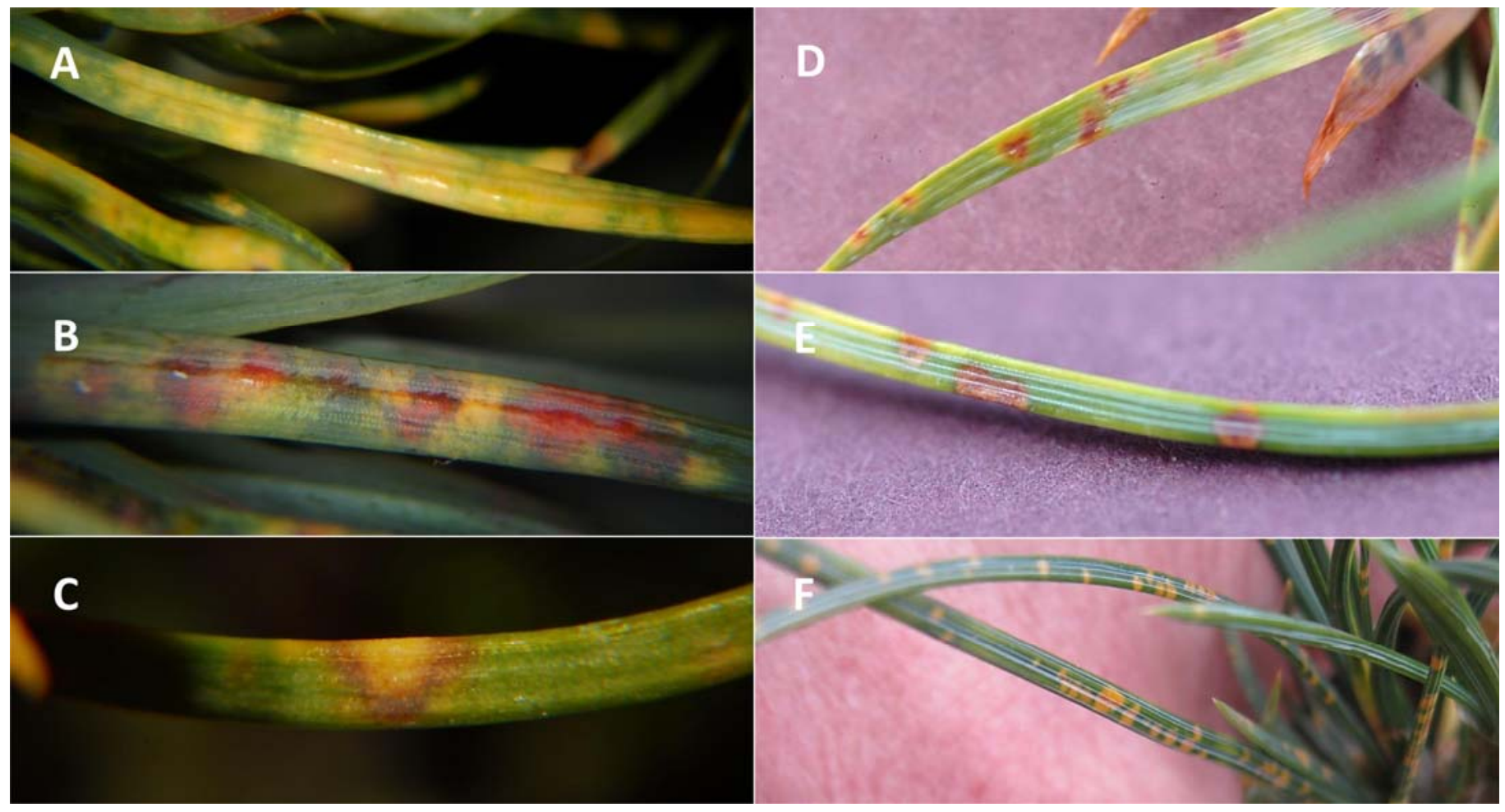

Fig. 2. Spot types on limber pine needles following artificial inoculation with Cronartium ribicola. Susceptible-type needle spots on seedlings that develop white pine blister rust on $\mathbf{A}$, secondary needle and $\mathbf{B}$, primary needle; discrete necrotic-type spots on a $\mathbf{C}$, cotyledon; $\mathbf{D}$, primary needle; and $\mathbf{E}$ and $\mathbf{F}$, secondary needle on seedlings that remain stem-symptom-free. Spots such as shown in image $\mathrm{C}$ were rare. 
WPBR). However, the G frequencies between WPBR-challenged and unchallenged populations were only slightly different (Table 6 ). The $\mathrm{G}$ frequency of the $R$ allele varied widely among sites in this modest sampling from 0.000 to 0.139 . Including all 105 seed trees in trials 06-06 and 07-07, the measured genotypic frequencies were not significantly different from the expectations of the Hardy-Weinberg equilibrium (Table 7, $P>0.05$ ).

\section{DISCUSSION}

Results from these inoculation trials led to several conclusions regarding limber pine in the Southern Rocky Mountains: (i) genetic segregation of a SS-free trait to blister rust exists that is consistent with inheritance by a single dominant $R$ gene, (ii) spot and needle necrosis traits are also associated with the complete resistance, and (iii) the $R$ allele in limber pine responds differently than the $R$ allele in western white pine when exposed to the $v c r 2$ virulent strain of the rust. Following the past criteria for $R$ genes in other white pine species (30) and established naming conventions (54), we are designating the $R$ gene for limber pine as Cr4.
A family structure (versus previous tests using bulk seed lots) provides the materials needed to examine inheritance. This is the first series of studies to use individual families to examine complete resistance to WPBR and its inheritance in limber pine. We found $14 \%$ of the tested families to show a $1: 1$ or $3: 1$ segregation ratio for SS-free/SS-present, consistent with inheritance by

TABLE 3. Reduction in needle spots on live needles over time as a consequence of premature needle necrosis in young seedlings that remain stem symptom (SS)-free after inoculation with Cronartium ribicola in trial 06-06

\begin{tabular}{lcc}
\hline & \multicolumn{2}{c}{ Seedlings with needle spots (\%) } \\
\cline { 2 - 3 } Phenotype, time $^{\mathrm{a}}$ & Present $^{\mathrm{b}}$ & Absent $^{\mathrm{b}}$ \\
\hline SSs present & & 7 \\
2 months & 93 & 11 \\
12 months & 89 & 4 \\
SSs absent & 96 & 91 \\
2 months & 9 & \\
12 months & & \\
\hline
\end{tabular}

a Final seedling phenotype and time of spot assessment postinoculation. b Percentage of seedlings with or without spots present on live needles.

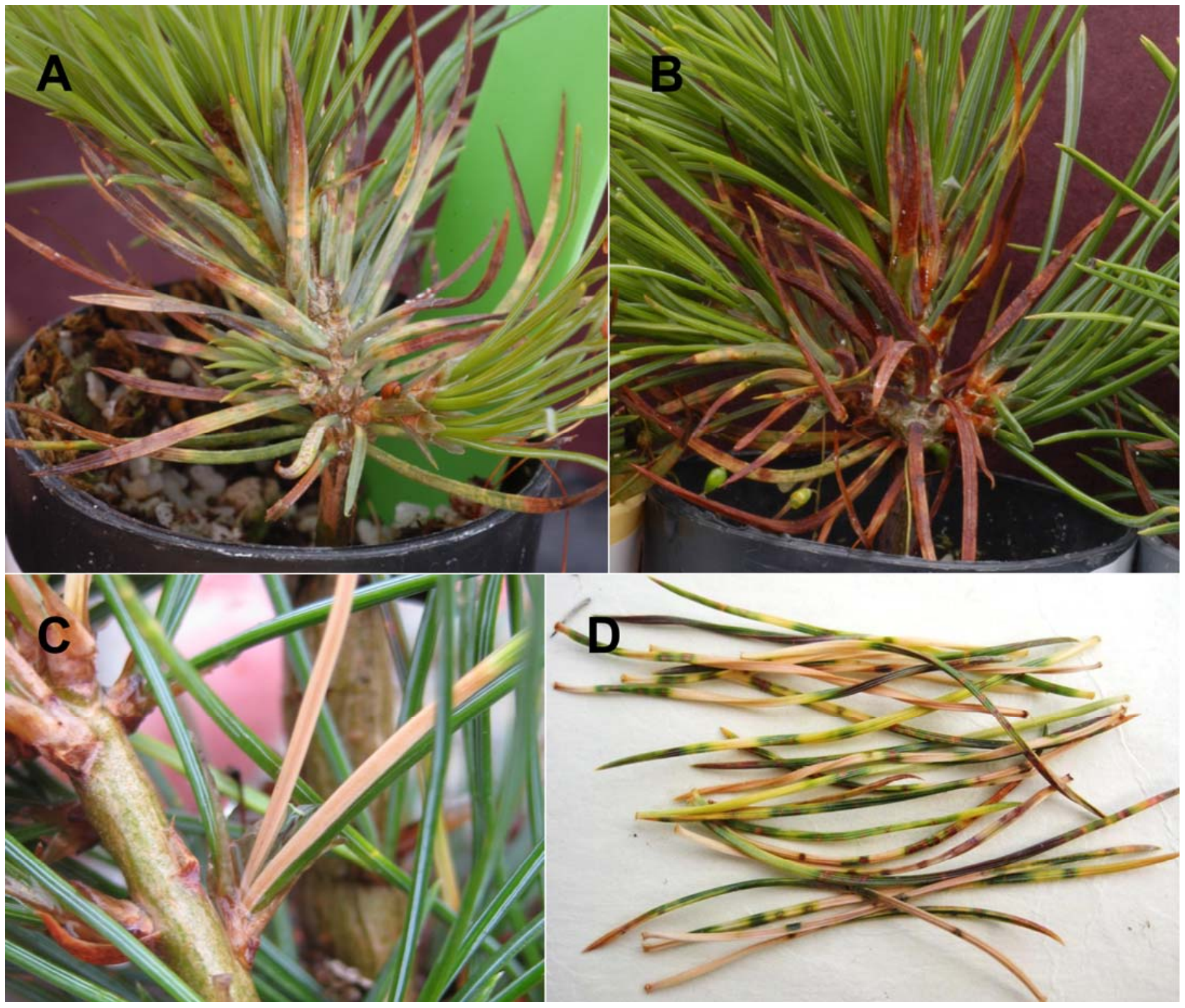

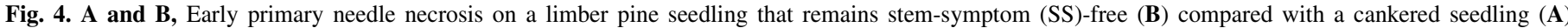

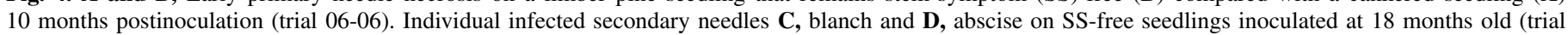
06-07). Note green-island spot-types on some abscised needles (D). 
a single dominant gene. This confirms limber pine as the fourth North American white pine species to show a major gene for resistance to WPBR, the others being sugar, western white, and southwestern white pine, with $\mathrm{Cr} 1, \mathrm{Cr} 2$, and $\mathrm{Cr} 3$, respectively (30-33). In the three other species, the $R$ alleles appear to be distinct for each species and virulence in the pathogen has evolved to two $R$ genes consistent with the gene-for-gene hypothesis (13). We suspect that the limber pine $R$ allele is likewise distinct. In an ongoing study (trial 07-08b), the expression of resistance in several limber pine families whose progeny segre-

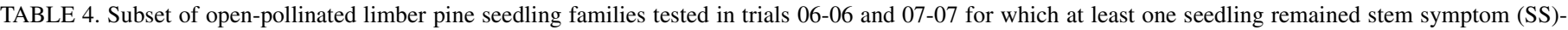
free over the 24-month postinoculation period ${ }^{a}$

\begin{tabular}{|c|c|c|c|c|c|c|c|}
\hline \multirow[b]{2}{*}{ Year $^{b}$} & \multirow[b]{2}{*}{ Seed tree ID } & \multirow[b]{2}{*}{ Infection status ${ }^{\mathrm{c}}$} & \multirow[b]{2}{*}{$N^{\mathrm{d}}$} & \multirow[b]{2}{*}{ Progeny SS-free $(\%)$} & \multicolumn{3}{|c|}{$P$ for $\chi^{2}$ test $\mathrm{SS}$-free/SS segregation } \\
\hline & & & & & $1: 1$ & $3: 1$ & $1: 3$ \\
\hline 2007 & 1 & Putatively resistant & 35 & 63 & 0.1282 & 0.0971 & 0.0000 \\
\hline 2006 & 2 & Putatively resistant & 23 & 57 & 0.5316 & 0.0407 & 0.0005 \\
\hline 2007 & 3 & Putatively resistant & 21 & 57 & 0.5212 & 0.0568 & 0.0007 \\
\hline 2006 & 4 & Putatively resistant & 25 & 56 & 0.5485 & 0.0282 & 0.0003 \\
\hline 2006 & 3 & Putatively resistant & 13 & 54 & 0.7730 & 0.0804 & 0.0157 \\
\hline 2007 & 6 & Putatively resistant & 24 & 54 & 0.6951 & 0.0175 & 0.0010 \\
\hline 2006 & 7 & Putatively resistant & 26 & 50 & 1.0000 & 0.0032 & 0.0032 \\
\hline 2007 & 8 & Putatively resistant & 32 & 50 & 1.0000 & 0.0011 & 0.0011 \\
\hline 2007 & 9 & Putatively resistant & 21 & 43 & 0.5212 & 0.0007 & 0.0568 \\
\hline 2007 & 10 & Putatively resistant & 27 & 41 & 0.3359 & 0.0000 & 0.0589 \\
\hline 2006 & 11 & Putatively resistant & 13 & 31 & 0.1707 & 0.0002 & 0.6174 \\
\hline 2007 & 12 & Putatively resistant & 21 & 29 & 0.0495 & 0.0000 & 0.7055 \\
\hline 2006 & 13 & Putatively resistant & 20 & 15 & 0.0017 & 0.0000 & 0.3017 \\
\hline 2006 & 14 & Putatively resistant & 16 & 13 & 0.0027 & 0.0000 & 0.2482 \\
\hline 2007 & 15 & Putatively resistant & 15 & 13 & 0.0042 & 0.0000 & 0.2831 \\
\hline 2007 & 16 & Putatively resistant & 27 & 11 & 0.0001 & 0.0000 & 0.0930 \\
\hline 2006 & 17 & Putatively resistant & 22 & 9 & 0.0001 & 0.0000 & 0.0831 \\
\hline 2006 & 18 & Putatively resistant & 24 & 8 & 0.0000 & 0.0000 & 0.0593 \\
\hline 2007 & 19 & Putatively resistant & 12 & 8 & 0.0036 & 0.0000 & 0.1738 \\
\hline 2007 & 20 & Putatively resistant & 24 & 8 & 0.0000 & 0.0000 & 0.0593 \\
\hline 2007 & 21 & Putatively resistant & 35 & 6 & 0.0000 & 0.0000 & 0.0084 \\
\hline 2007 & 22 & Putatively resistant & 36 & 6 & 0.0000 & 0.0000 & 0.0071 \\
\hline 2007 & 23 & Putatively resistant & 21 & 5 & 0.0000 & 0.0000 & 0.0322 \\
\hline 2007 & 44 & Susceptible & 33 & 15 & 0.0001 & 0.0000 & 0.1846 \\
\hline 2006 & 45 & Susceptible & 21 & 14 & 0.0011 & 0.0000 & 0.2568 \\
\hline 2006 & 46 & Susceptible & 26 & 8 & 0.0000 & 0.0000 & 0.0415 \\
\hline 2006 & 47 & Susceptible & 12 & 8 & 0.0036 & 0.0000 & 0.1738 \\
\hline 2007 & 48 & Susceptible & 35 & 6 & 0.0000 & 0.0000 & 0.0084 \\
\hline 2006 & 49 & Susceptible & 24 & 4 & 0.0000 & 0.0000 & 0.0175 \\
\hline 2007 & 50 & Susceptible & 36 & 3 & 0.0000 & 0.0000 & 0.0021 \\
\hline 2006 & 58 & Not challenged & 23 & 91 & 0.0001 & 0.0710 & 0.0000 \\
\hline 2006 & 59 & Not challenged & 12 & 75 & 0.0833 & 1.0000 & 0.0001 \\
\hline 2006 & 60 & Not challenged & 23 & 61 & 0.2914 & 0.1210 & 0.0001 \\
\hline 2007 & 59 & Not challenged & 35 & 54 & 0.6121 & 0.0047 & 0.0001 \\
\hline 2006 & 62 & Not challenged & 33 & 42 & 0.3841 & 0.0000 & 0.0208 \\
\hline 2006 & 63 & Not challenged & 34 & 41 & 0.3035 & 0.0000 & 0.0294 \\
\hline 2006 & 64 & Not challenged & 21 & 19 & 0.0045 & 0.0000 & 0.5254 \\
\hline 2006 & 65 & Not challenged & 18 & 17 & 0.0047 & 0.0000 & 0.4142 \\
\hline 2006 & 66 & Not challenged & 36 & 17 & 0.0001 & 0.0000 & 0.2482 \\
\hline 2006 & 67 & Not challenged & 25 & 16 & 0.0007 & 0.0000 & 0.2987 \\
\hline 2006 & 68 & Not challenged & 23 & 15 & 0.0018 & 0.0000 & 0.3994 \\
\hline 2006 & 69 & Not challenged & 30 & 13 & 0.0001 & 0.0000 & 0.1400 \\
\hline 2006 & 70 & Not challenged & 25 & 12 & 0.0001 & 0.0000 & 0.1333 \\
\hline 2006 & 71 & Not challenged & 29 & 10 & 0.0000 & 0.0000 & 0.0684 \\
\hline 2006 & 72 & Not challenged & 20 & 10 & 0.0003 & 0.0000 & 0.1213 \\
\hline 2006 & 73 & Not challenged & 30 & 10 & 0.0000 & 0.0000 & 0.0578 \\
\hline 2006 & 74 & Not challenged & 32 & 9 & 0.0000 & 0.0000 & 0.0412 \\
\hline 2006 & 75 & Not challenged & 25 & 8 & 0.0000 & 0.0000 & 0.0496 \\
\hline 2006 & 76 & Not challenged & 22 & 7 & 0.0001 & 0.0000 & 0.0848 \\
\hline 2006 & 77 & Not challenged & 15 & 7 & 0.0008 & 0.0000 & 0.1011 \\
\hline 2006 & 78 & Not challenged & 17 & 6 & 0.0003 & 0.0000 & 0.0704 \\
\hline 2006 & 79 & Not challenged & 20 & 5 & 0.0001 & 0.0000 & 0.0389 \\
\hline 2006 & 80 & Not challenged & 20 & 5 & 0.0001 & 0.0000 & 0.0389 \\
\hline 2006 & 81 & Not challenged & 21 & 5 & 0.0000 & 0.0000 & 0.0322 \\
\hline 2006 & 82 & Not challenged & 27 & 4 & 0.0000 & 0.0000 & 0.0106 \\
\hline 2006 & 83 & Not challenged & 28 & 4 & 0.0000 & 0.0000 & 0.0088 \\
\hline 2006 & 84 & Not challenged & 27 & 4 & 0.0000 & 0.0000 & 0.0106 \\
\hline
\end{tabular}

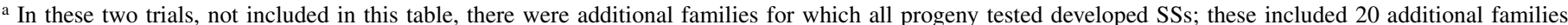
from seed trees showing no signs of disease (putatively resistant) from populations invaded by the white pine blister rust (WPBR), 6 additional families from seed trees cankered in the field, and 24 additional families from seed trees from populations not yet challenged by WPBR in the field. $P$ is reported for the $\chi^{2}$ test used to test the fit to the expected segregation ratios. Note that this table includes two tests for the progenies of seed trees 3 and 59 and the data for seed tree 58 fit the expected segregation ratio of 1:0 (SS-free/SS, $P>0.05)$. Bold entries depict the ratio for which the data fit $(P>0.05)$.

$\mathrm{b}$ Inoculation year.

c Field infection status of seed tree.

${ }^{\mathrm{d}}$ Number of progeny tested. 
gate 1:1 for the SS-free trait was not overcome by the source of $C$. ribicola with the virulent $v c r 2$ genotype, suggesting that the limber pine $R$ gene is distinct from $\mathrm{Cr} 2$ gene in western white pine (Table 5). A field trial including limber pine families heterozygous for $\mathrm{Cr} 4$ is underway in Happy Camp, CA, an area where the trees are exposed to $C$. ribicola with a high frequency

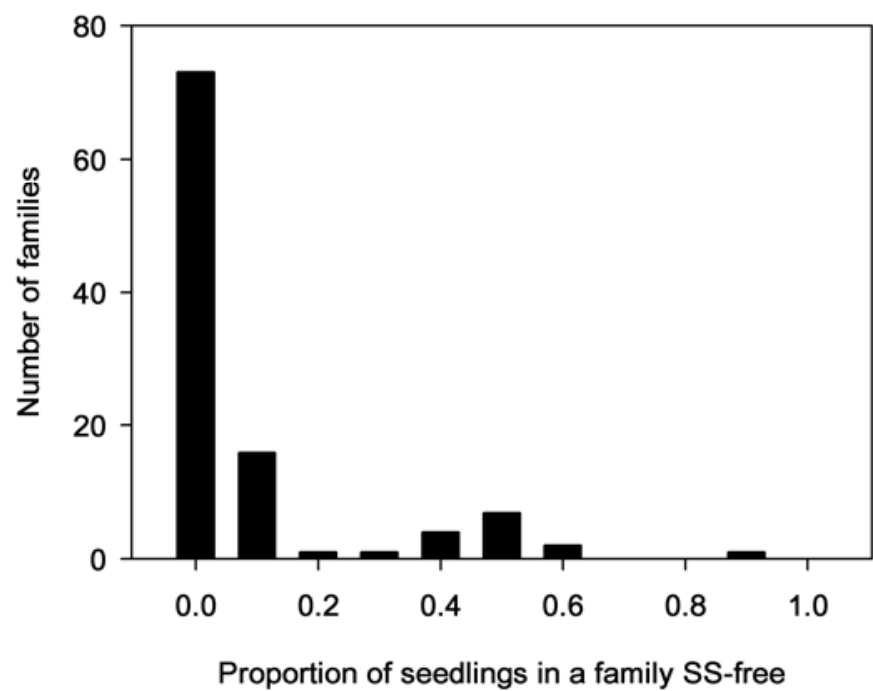

Fig. 5. Histogram of the number of families by the proportion of the progeny, by class, that remain stem-symptom-free following inoculation with Cronartium ribicola. Proportion classes are 0.0 to $0.09,0.10$ to 0.19 .0 .20 to 0.29 , and so on. Table 4 provides more detail on the proportion of progeny SS-free in each family. For those families tested more than once, the trial with wild-type inoculum for which the family had the greatest sample size is included here. of the vcrl gene. Virulence to the $\mathrm{Cr} 3$ gene in southwestern white pine has not yet been identified. Southwestern white pine and limber pine are suspected to naturally hybridize in the far southern portion of the Rocky Mountains (49) (south of our sampling areas); therefore, it is plausible that they share the same $\mathrm{Cr}$ gene, though this would be highly unusual for $R$ genes. Until $\mathrm{Cr} 3$ and $\mathrm{Cr} 4$ are mapped or virulence is documented, it is not possible to test for functional distinction between the $R$ genes or alleles in limber and southwestern white pine in open-pollinated families. The presence of the SS-free trait and suspected $R$ allele in low frequencies $(<1: 1$ ratio) in some limber pine families suggests that the $R$ allele may have been introduced to those progenies via pollen from one or more nearby reproductive parent trees with the allele. The observation that several of these seed trees are diseased in the field further supports the inference that those seed trees do not carry the $R$ allele. In light of the above evidence, we suggest the it is parsimonious at this time to refer to the SS-free resistance gene in limber pine as $\mathrm{Cr} 4$, following the criteria of Kinloch et al. (30) for naming $R$ alleles in other white pine species and established naming conventions (54).

The HR-type spot, diagnostic of $\mathrm{Cr} 1, \mathrm{Cr} 2$, and $\mathrm{Cr} 3$ in the other white pine species, with a necrotic margin typical of an HR (2933), was often not obvious in $\mathrm{Cr} 4$ limber pine. Discrete necrotic spots were more commonly seen on SS-free limber pine seedlings. In contrast to the other species, where spot-type on cotyledons in the first 4 to 6 months after inoculation of young seedlings under greenhouse conditions is diagnostic of the presence or absence of $\mathrm{Cr}$ resistance $(29,30)$, spot type alone at this early stage is a poor predictor of resistance in limber pine. Further refinements in technique (age, size, and culture of seedlings) could lead to such an assay in limber pine but is beyond the scope of this article.

TABLE 5. Comparison of trial outcomes of families in trial 06-06 that were also included in other inoculation trials ${ }^{\mathrm{a}}$

\begin{tabular}{|c|c|c|c|c|c|c|c|c|}
\hline \multirow[b]{2}{*}{ Seed tree ID } & \multirow[b]{2}{*}{ Trial } & \multirow[b]{2}{*}{ Source ${ }^{b}$} & \multirow[b]{2}{*}{ Infection status ${ }^{\mathrm{c}}$} & \multirow[b]{2}{*}{$N^{\mathrm{d}}$} & \multirow[b]{2}{*}{ Progeny SS-free $(\%)$} & \multicolumn{3}{|c|}{$P$ for $\chi^{2}$ test SS-free/SS segregation } \\
\hline & & & & & & $1: 1$ & $3: 1$ & $1: 3$ \\
\hline 59 & $06-06$ & WT & Not challenged & 12 & 75 & 0.0833 & 1.0000 & 0.0001 \\
\hline 59 & 07-07 & WT & Not challenged & 35 & 54 & 0.6121 & 0.0047 & 0.0001 \\
\hline 59 & $07-08 b$ & WT+ver2 & Not challenged & 32 & 53 & 0.7343 & 0.0041 & 0.0003 \\
\hline 59 & 07-08a & WT & Not challenged & 32 & 56 & 0.4795 & 0.0143 & 0.0000 \\
\hline 63 & 06-06 & WT & Not challenged & 34 & 41 & 0.3035 & 0.0000 & 0.0294 \\
\hline 63 & $07-08 b$ & $\mathrm{WT}+\mathrm{ver} 2$ & Not challenged & 31 & 45 & 0.5777 & 0.0001 & 0.0101 \\
\hline 63 & $07-08 \mathrm{a}$ & WT & Not challenged & 32 & 66 & 0.0771 & 0.2207 & 0.0000 \\
\hline 74 & $06-06$ & WT & Not challenged & 32 & 9 & 0.0000 & 0.0000 & 0.0412 \\
\hline 74 & $07-08 b$ & $\mathrm{WT}+\mathrm{ver} 2$ & Not challenged & 32 & 6 & 0.0000 & 0.0000 & 0.0143 \\
\hline 74 & 07-08a & WT & Not challenged & 32 & 0 & 0.0000 & 0.0000 & 0.0011 \\
\hline 113 & $06-06$ & WT & Putatively resistant & 13 & 31 & 0.1707 & 0.0002 & 0.6174 \\
\hline 113 & $07-08 b$ & WT+ver2 & Putatively resistant & 32 & 53 & 0.7343 & 0.0041 & 0.0003 \\
\hline 113 & $07-08 \mathrm{a}$ & WT & Putatively resistant & 32 & 41 & 0.2888 & 0.0000 & 0.0412 \\
\hline 31 & 06-06 & WT & Putatively resistant & 32 & 0 & 0.0000 & 0.0000 & 0.0011 \\
\hline 31 & $07-08 b$ & $\mathrm{WT}+\mathrm{ver} 2$ & Putatively resistant & 24 & 4 & 0.0000 & 0.0000 & 0.0175 \\
\hline 31 & 07-08a & WT & Putatively resistant & 32 & 0 & 0.0000 & 0.0000 & 0.0011 \\
\hline 3 & $06-06$ & WT & Putatively resistant & 13 & 54 & 0.7730 & 0.0804 & 0.0157 \\
\hline 3 & 07-07 & WT & Putatively resistant & 21 & 57 & 0.5212 & 0.0568 & 0.0007 \\
\hline 51 & $06-06$ & WT & Infected & 17 & 0 & 0.0000 & 0.0000 & 0.0173 \\
\hline 51 & 07-07 & WT & Infected & 32 & 0 & 0.0000 & 0.0000 & 0.0011 \\
\hline 103 & $06-06$ & WT & Not challenged & 13 & 0 & 0.0003 & 0.0000 & 0.0374 \\
\hline 103 & $07-07$ & WT & Not challenged & 33 & 0 & 0.0000 & 0.0000 & 0.0009 \\
\hline 103 & 07-08a & WT & Not challenged & 32 & 0 & 0.0000 & 0.0000 & 0.0011 \\
\hline 106 & 06-06 & WT & Not challenged & 13 & 0 & 0.0003 & 0.0000 & 0.0374 \\
\hline 106 & 07-07 & WT & Not challenged & 12 & 0 & 0.0005 & 0.0000 & 0.0455 \\
\hline 90 & $06-06$ & WT & Not challenged & 13 & 0 & 0.0003 & 0.0000 & 0.0374 \\
\hline 90 & $07-07$ & WT & Not challenged & 31 & 0 & 0.0000 & 0.0000 & 0.0013 \\
\hline 92 & $06-06$ & WT & Not challenged & 13 & 0 & 0.0003 & 0.0000 & 0.0374 \\
\hline 92 & $07-07$ & WT & Not challenged & 30 & 0 & 0.0000 & 0.0000 & 0.0016 \\
\hline
\end{tabular}

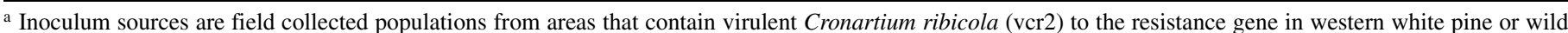
type (WT) that does not contain virulent genes (WT, avcr). $P$ is reported for the $\chi^{2}$ test used to test the fit to the expected segregation ratios. SS = stem symptom. Bold entries depict the ratio for which the data fit $(P>0.05)$.

b Inoculum source.

c Field infection status of seed tree.

d Number of progeny tested. 
Assessment of $\mathrm{Cr} 4$ in limber pine is dependably inferred from segregation data of the SS-free trait 15 to 24 months after inoculation of young seedlings. However, relying on the SS-free trait may underestimate the incidence of $\mathrm{Cr} 4$ if some expression is incomplete (i.e., "leakage" or suppressed by modifier genes), as has been seen in $C r 1$ and $C r 2(8,29,33)$. Such incomplete expression may explain the few diseased progeny for seed tree $58(91 \%$ $\mathrm{SS}$-free) if the seed tree is, in fact, $\mathrm{Cr} 4 \mathrm{Cr} 4$. Alternatively, seed tree 58 may be heterozygous for $\mathrm{Cr} 4$ but be in close proximity to a pollen donor that is homozygous for $\mathrm{Cr} 4$. It is also possible that seed tree 58 may be heterozygous for two unlinked dominant resistance genes, $\mathrm{Cr} 4$ and another $\mathrm{Cr}$ gene, for which the wildtype inoculum is avirulent; additional research with this family would provide more insight. In comparison, $>5,000$ parent trees of western white pine and sugar pine have been screened and a second $R$ gene has not been found in either species, though it may occur in another species. Overall, in this set of experiments, the ratios of SS-free to SS seedlings for segregating limber pine families were extremely consistent with the expected $1: 1$ ratio for a single segregating $R$ gene.

The lack of SS development on $\mathrm{Cr} 4$ seedlings suggests that the resistance to disease development is at the needle level or needlestem junction and may or may not be at the point of infection, as would be expected if mediated by a classic HR. The widespread association of the HR cell death with the gene-for-gene resistance in vascular plants suggests that it confers an adaptive benefit but it may not be essential for successful restriction of pathogen growth in some interactions (55). Recent histological evaluation of $\mathrm{Cr} 2$ western white pine suggests that the necrotic margin of the HRtype spot is not containing fungal growth (51). Likewise, the speed of development of the HR-type spot phenotype in pine is slow (months) compared with classic HR (hours to days) in other plant species. As has been suggested in other plant species, cell death within the HR may act more as a signal within the plant than as a direct defense mechanism (15). Further histological evaluation of susceptible and $\mathrm{Cr} 4$ limber pine, $\mathrm{Crl}$ sugar pine, and $\mathrm{Cr} 2$ western white pine is underway to provide insights into the underlying processes of these major gene resistance mechanisms.

Other associated traits with the SS-free phenotype may provide further hypotheses regarding the resistance reaction. The early necrosis of infected needles in $\mathrm{Cr} 4$ seedlings compared with uninoculated or diseased limber pine seedlings and the observation that only infected needles prematurely senesce suggests a hostmediated needle necrosis response to infection. Early SSs on susceptible limber pine seedlings (cr4cr4) began appearing months before needle necrosis on resistant seedlings, suggesting that the timing of needle necrosis or shed may be too slow to prevent unimpeded fungal growth into the stem. In addition, most but not all of the infected needles on some $\mathrm{Cr} 4$ seedlings prematurely died, suggesting that the needle death is likely a consequence of resistance expression rather than the mechanism. Needle blight has also been associated with $C r l$ sugar pine seedlings (31) and suspected in $\mathrm{Cr} 2$ western white pine (26). Likewise, early leaf senescence is also associated with pathogenesis-related (PR) proteins and HR response in other vascular plants (7). In western

TABLE 6. Zygotic and gametic frequencies of the $\mathrm{Cr} 4$ allele that confers the stem-symptom-free trait in populations challenged by white pine blister rust (WPBR), those not challenged by WPBR, and overall as tested in trials 06-06 and $07-07^{\mathrm{a}}$

\begin{tabular}{lcccc}
\hline Site name & $\begin{array}{c}\text { Number of seed } \\
\text { trees tested }\end{array}$ & $\begin{array}{c}\text { Zygotic } \\
\text { frequency }\end{array}$ & $\begin{array}{c}\text { Gametic } \\
\text { frequency }\end{array}$ & $\begin{array}{c}\text { Number of } \\
\text { seedlings }\end{array}$ \\
\hline Challenged & 55 & 0.09091 & 0.04882 & 1,120 \\
Unchallenged & 50 & 0.05000 & 0.05141 & 1,083 \\
Overall & 105 & 0.07143 & 0.05012 & 2,203 \\
\hline
\end{tabular}

a See text for calculations. white pine, for some parent trees without $\mathrm{Cr} 2$ resistance, early needle shed has been suggested as a separate resistance mechanism controlled by recessive genes (37) yet its role as a resistance mechanism has been questioned (21). In the case of limber pine, shedding in $\mathrm{Cr} 4$ trees presumably indicates a signal cascade to infection. Furthermore, stem stiffness was recorded for some $\mathrm{Cr} 4$ limber pine seedlings. suggesting the possibility of some reaction in the stem to inoculation whether by chemical signaling or direct fungal contact in the stem tissue. Irregular stem morphology but no WPBR disease symptoms has also been reported in some $\mathrm{Crl}$ sugar pine seedlings (31). Research on fungal colonization in needles and stems and host physiology over time will help determine the location of resistance reactions.

The frequency of the $\mathrm{Cr} 4$ allele in limber pine in the Southern Rocky Mountains is estimated at $5.0 \%$ and shows greater variation among sites ( 0 to $13.9 \%$ ) than has been observed for $\mathrm{Crl}$ and $C r 2(28,34)$. Even though limber pine has not co-evolved with $C$. ribicola, the $\mathrm{Cr} 4$ frequency in the Southern Rocky Mountains is far above the expected mutation rate $\left(\approx 10^{-6}\right)$ and was unexpectedly high compared with $\mathrm{Cr} 2$ in western white pine $(<0.1 \%$; range of 0 to $0.8 \%$ ) (34) and $C r 1$ in sugar pine range-wide $(2.2 \%$; range of 0 to $8.9 \%$ ) (28). Either the Southern Rocky Mountains are a $\mathrm{Cr} 4$ hotspot or the incidence of this allele is higher than in both of the generally lower elevation species. The Southern Rocky Mountains are just one portion of the limber pine distribution that extends northward into Alberta and west to California. The 1:1 segregating SS-free trait (i.e., $\mathrm{Cr} 4$ ) has not been detected in the few seed lots and families tested from other parts of the distribution $(30,53)$; a thorough range-wide assessment has not yet been undertaken.

The measured genotypic frequencies (seed tree genotype inferred from progeny testing) of $\mathrm{Cr} 4$ are consistent with the expectations of the Hardy-Weinberg equilibrium. This further suggests that $\mathrm{Cr} 4$ is not a product of a recent mutation and may provide other adaptive significance within limber pine, possibly related to other stress factors, as is often the case in other species with $R$ genes (7). PR proteins of the PR-10 family are differentially expressed in some white pine trees in response to both WPBR infection and cold hardening, suggesting a mechanism of cross-communication between these external stimuli (12). The expression of PR-10 genes is also induced by other abiotic stresses such as salinity and drought in other plant species (35). Additionally, it has been hypothesized that the $\mathrm{Cr}$ genes played a role in protecting the pines against other pathogens in the past and exposure to those pathogens served as selective agents for the $\mathrm{Cr}$ genes (34). The relationships between disease resistance, abiotic stress tolerances, and past exposure to other pathogens may provide insights into the origin of resistance mechanisms in plants to invasive pathogens with which they have not co-evolved.

Finally, equilibrium also suggests no current directional natural selective pressure on the gene in these populations. Because our sampling and, therefore, the population for which we are making inference contained only reproductive trees, it is likely that selection by WPBR has not yet affected the limber pine mating population in the Southern Rocky Mountains. WPBR had not invaded or only relatively recently invaded the sampled popula-

TABLE 7. Measured genotypic frequencies were not significantly different from the expectations of the Hardy-Weinberg equilibrium ${ }^{\mathrm{a}}$

\begin{tabular}{lccc}
\hline Genotype & $\begin{array}{c}\text { Observed number } \\
\text { of seed trees }\end{array}$ & $\begin{array}{c}\text { Expected number } \\
\text { of seed trees }\end{array}$ & $\chi^{2}$ \\
\hline cr4cr4 & 90 & 89.6 & 0.0017 \\
Cr4cr4 & 14 & 14.8 & 0.0413 \\
Cr4Cr4 & 1 & 0.6 & 0.2501 \\
Total & 105 & 105 & 0.2931 \\
\hline
\end{tabular}

a At 1 degree of freedom, critical $\chi^{2}$ at $\alpha=0.05$ is 3.841 . 
tions and, thus far, has not caused significant mortality in the mature tree cohort (25). The similar $\mathrm{G}$ frequencies of $\mathrm{Cr} 4$ in WPBR-challenged and unchallenged stands further suggests that WPBR has not yet affected the mating population. As WPBR pressure increases and selection intensifies, barring the evolution of virulence in the rust, we suspect the genotypic frequency of the $\mathrm{Cr} 4$ allele will increase and no longer be in equilibrium. For the WPBR-infected sites, this may already be the case in the younger tree cohorts; however, this cannot be tested until enough time has elapsed for this young cohort to become seed bearing or molecular techniques are developed to identify the $\mathrm{Cr} 4$ genotype of nonreproductive individuals.

In summary, these results are consistent with the presence of a dominant $R$ gene in limber pine, named $\mathrm{Cr} 4$, which confers complete resistance to WPBR. The frequency of the dominant $\mathrm{Cr} 4$ allele is high enough for detection from modest sample levels in seed collections from trees in populations not yet invaded by $C$. ribicola, as well as in disease-free trees in populations in the early stages of WPBR infestation. $\mathrm{Cr} 4$ is effective under exposure to the vcr2 gene, suggesting that the $\mathrm{Cr} 4$ gene or $\mathrm{Cr} 4$ allele is distinct from $\mathrm{Cr} 2$ in western white pine. Tests are underway to confirm that $\mathrm{Cr} 4$ is effective under challenge with $C$. ribicola with $v c r l$, which is virulent to $C r l$ in sugar pine. The question of how the $C r$ genes in the North American white pine evolved in the absence of past exposure to $C$. ribicola remains a puzzle $(30,34)$. The possibility that abiotic stress tolerances may relate to disease resistance functions deserves further study in novel pathosystems. Geographic distribution of $\mathrm{Cr} 4$ can help provide the basis of hypotheses and will be addressed in a subsequent article.

The limber pine seed trees that our trials reveal to have the $\mathrm{Cr} 4$ allele will serve as monitors for the evolution of the vcr4 virulent gene in $C$. ribicola. To date, the $\mathrm{Cr} 4$ trees in populations sampled here and exposed to WPBR for $>20$ years remain disease-free. The combination of low stand densities and open canopies of Southern Rocky Mountain limber pine stands (43) and the lack of a strong relationship between proximity to Ribes (the alternate host for $C$. ribicola) and disease incidence in limber pine (24) suggests long-distant transport of $C$. ribicola spores in these ecosystems. The atmospheric mixing of spores from multiple $C$. ribicola populations over extensive landscapes of conifer forests may reduce localized selection pressure on $C$. ribicola and, therefore, slow co-evolution of virulence. Although virulence evolved in $C$. ribicola to $C r 1$ and $C r 2$ in North America in less than a century, two Eurasian white pine species, $P$. armandii $(18,36,45)$ and $P$. morrisoncola (R. Sniezko, unpublished data), that are presumed to have historically co-evolved with $C$. ribicola, continue to show evidence of $R$ gene resistance in artificial inoculation trials. More research on the ecology of the Eurasian species and epidemiology of WPBR in their ecosystems may provide insight into factors affecting the potential stability of $R$ genes in the WPBR-pathosystem. However, relying on $\mathrm{Cr} 4$ alone to sustain limber pine population into the future in the presence of increasing WPBR pressure is not recommended and investigations to identify other types of resistance to WPBR in limber pine are underway. The identification of $\mathrm{Cr} 4$ and other types of resistance in native populations of limber pine early in the invasion progress in this region provides useful information for predicting near-term impacts and structuring long-term management strategies (42).

\section{ACKNOWLEDGMENTS}

This research was funded by an award from the USDA Forest Service Special Technology Development Program (R2-2006-02) and an agreement from USDI Park Service Great Sand Dunes National Park and Preserve (08-IA-11221633-304 and 08-IA-11221633-305). We thank R. Danchok, S. Long, B. Mayo, J. Hill, B. Luis, I. Lebouc, and K. Joy for assistance with rust assessments; L. Riley and the DGRC nursery crew for plant culture work; B. Kinloch, Jr. and P. Zambino for helpful discussions; P. Vogan for comments on an earlier version of the manuscript and two anonymous reviewers. A. Schoettle, R. Sniezko, and J. Hill provided the photos in Figures 2 and 4.

\section{LITERATURE CITED}

1. Bedwell, J. L., and Childs, T. W. 1943. Susceptibility of white-bark pine to blister rust in the Pacific Northwest. J. For. 41:904-912.

2. Bingham, R. T. 1972. Taxonomy, crossability, and relative blister rust resistance of 5-needled white pines. Pages 271-278 in: Biology of Rust Resistance in Forest Trees: Proc. NATO-IUFRO Advanced Study Inst. U. S. Dep. Agric. For. Serv. Misc. Publ. No 1221. Washington, DC.

3. Blodgett, J. T., and Sullivan, K. F. 2004. First report of white pine blister rust on Rocky Mountain bristlecone pine. Plant Dis. 88:311.

4. Brown, D. H. 1978. Extension of the known distribution of Cronartium ribicola and Arceuthobium cyanocarpum on limber pine in Wyoming. Plant Dis. Rep. 62:905.

5. Burns, K. S., Schoettle, A. W., Jacobi, W. R., and Mahalovich, M. F. 2008. Options for the management of white pine blister rust in the Rocky Mountain Region. Gen. Tech. Rep. RMRS-GTR-206. United States Department of Agriculture, Forest Service, Rocky Mountain Research Station, Fort Collins, CO.

6. Childs, T. W., and Bedwell, J. L. 1948. Susceptibility of some white pine species to Cronartium ribicola in the Pacific Northwest. J. For. 46:595599.

7. Collinge, D. B., and Slusarenko, A. J. 1987. Plant gene expression in response to pathogens. Plant Mol. Biol. 9:389-410.

8. Danchok, R. S., Sniezko, R. A., Long, S., Kegley, A., Savin, D., Mayo, J. B., Liu, J. J., and Hill, J. 2012. Frequency of hypersensitive-like reaction and stem infections in a large full-sib family of Pinus monticola. Pages 281-285 in: Proc. Fourth Int. Workshop Genet. Host-Parasite Interact. For. Disease and Insect Resistance in Forest Trees. R. A. Sniezko, A. D. Yanchuk, J. T. Kliejunas, K. M. Palmieri, J. M. Alexander, and S. J. Frankel, tech. coord. Eugene, OR. Gen. Tech. Rep. PSW-GTR-240. United States Department of Agriculture, Forest Service, Pacific Southwest Research Station, Albany, CA.

9. Delatour, C., and Birot, Y. 1982. The international IUFRO experiment on resistance of white pines to blister rust (Cronartium ribicola). The French trial. Pages 412-414 in: Resistance to Diseases and Pests in Forest Trees. Proc. Third Int. Workshop Genet. Host-Parasite Interact. For. H. M. Heybroek, B. R. Stephan, and K. von Weissenberg, eds. Centre for Agricultural Publishing and Documentation, Wageningen, The Netherlands.

10. Dhir, N., Allen, L., and Vujnovic, K. 2003. Limber and whitebark pine management in Alberta. Pages 10-11 in: Whitebark and Limber Pine Workshop, Calgary, AB, Canada. S. Rasheed, ed. Parks Canada, Calgary, $\mathrm{AB}$, Canada.

11. Donnegen, J. A., and Rebertus, A. J. 1999. Rates and mechanisms of subalpine forest succession along an environmental gradient. Ecology 80:1370-1384

12. Ekramoddoullah, A. K. M., and Hunt, R. S. 2002. Challenges and opportunities in studies of host-pathogen interactions in forest tree species. Can. J. Plant Pathol. 24:408-415.

13. Flor, H. H. 1971. Current status of the gene-for-gene concept. Annu. Rev. Phytopathol. 9:275-296.

14. Government of Alberta Species assessed by Alberta's Endangered Species Conservation Committee: Short list online. http://srd.alberta.ca/FishWildlife/ SpeciesAtRisk/SpeciesSummaries/documents/SpeciesAssessed-Endangered SpeciesConservationCommittee-ShortList-Nov06-2012.pdf

15. Heath, M. C. 2000. Hypersensitive response-related death. Plant Mol. Biol. 44:321-334.

16. Hirt, R. R. 1940. Relative susceptibility to Cronartium ribicola of 5needled pines planted in the east. J. For. 38:932-937.

17. Hoff, R. J., Bingham, R. T., and McDonald, G. I. 1980. Relative blister rust resistance of white pines. Eur. J. For. Pathol. 10:307-316.

18. Hoff, R. J., and McDonald, G. I. 1972. Resistance of Pinus armandii to Cronartium ribicola. Can. J. For. Res. 2:303-307.

19. Hoff, R. J., McDonald, G. I., and Bingham, R. T. 1973. Resistance to Cronartium ribicola in Pinus monticola: Structure and gain of resistance in the second generation. Res. Note INT-178. United States Department of Agriculture, Forest Service, Intermountain Research Station, Ogden, UT.

20. Howell, B., Burns, K. S., Kearns, H. S. J., Witcosky, J. J., and Cross, F. J. 2006. Biological evaluation of a model for predicting presence of white pine blister rust in Colorado based on climatic variable and susceptible white pine species distribution. Biological Evaluation R2-06-04, Rocky Mountain Region Renewable Resources, United States Department of Agriculture, Forest Service, Lakewood, CO.

21. Hunt, R. S., Roke, G., and Jensen, G. D. 2007. Initiation of stem infection 
in western white pine by blister rust (Cronartium ribicola). Can. J. Plant Pathol. 29:18-24.

22. Johnson, D. W., and Jacobi, W. R. 2000. First report of white pine blister rust in Colorado. Plant Dis. 84:595.

23. Keane, R. E., and Schoettle, A. W. 2011. Strategies, tools, and challenges for sustaining and restoring high elevation five-needle white pine forests in western North America. Pages 276-294 in: The Future of HighElevation, Five-Needle White Pines in Western North America. Proc. High Five Symp. Missoula, MT. Proc. RMRS-P-63. R. E. Keane, D. F. Tomback, M. P. Murray, and C. M. Smith, eds. Unites States Department of Agriculture, Forest Service, Rocky Mountain Research Station, Fort Collins, CO.

24. Kearns, H. S. J. 2005. White pine blister rust in the central Rocky Mountains: Modeling current status and potential impacts. Dissertation, Colorado State University, Fort Collins.

25. Kearns, H. S. J., and Jacobi, W. R. 2007. The distribution and incidence of white pine blister rust in central and southeastern Wyoming and northern Colorado. Can. J. For. Res. 37:462-472.

26. Kegley, A. J., and Sniezko, R. A. 2004. Variation in Blister Rust Resistance Among 226 Pinus monticola and 217 P. lambertiana Seedling Families in the Pacific Northwest. Pages 209-226 in: Breeding and Genetic Resources of Five-Needle Pines: Growth, Adaptability, and Pest Resistance. IUFRO Working Party 2.02.15. Proc. RMRS-P-32. Medford, OR. R. A. Sniezko, S. Samman, S. E. Schlarbaum, and H. B. Kriebel, eds. United States Department of Agriculture, Forest Service, Rocky Mountain Research Station, Fort Collins, CO.

27. King, J. N., David, A., Noshad, D., and Smith, J. 2010. A review of genetic approaches to the management of blister rust in white pines. For. Pathol. 40:292-313.

28. Kinloch, B. B., Jr. 1992. Distribution and frequency of a gene for resistance to white pine blister rust in natural populations of sugar pine. Can. J. Bot. 70:1319-1323.

29. Kinloch, B. B., Jr., and Comstock, M. 1980. Cotyledon test for major gene resistance to white pine blister rust in sugar pine. Can. J. Bot. 58:1912-1914

30. Kinloch, B. B., Jr.,, and Dupper, G. E. 2002. Genetic specificity in the white pine-blister rust pathosystem. Phytopathology 92:278-280.

31. Kinloch, B. B., Jr.,, and Littlefield, J. L. 1977. White pine blister rust: hypersensitive resistance in sugar pine. Can. J. Bot. 55:1148-1155.

32. Kinloch, B. B., Jr., Parks, G. K., and Fowler, C. W. 1970. White pine blister rust: Simply inherited resistance in sugar pine. Can. J. Bot. 58:1912-1914

33. Kinloch, B. B., Jr., Sniezko, R. A., Barnes, G. D., and Greathouse, T. E. 1999. A major gene for resistance to white pine blister rust in western white pine from the western Cascade Range. Phytopathology 89:861-867.

34. Kinloch, B. B., Jr.,, Sniezko, R. A., and Dupper, G. E. 2003. Origin and distribution of $\mathrm{Cr} 2$, a gene for resistance to white pine blister rust in natural populations of western white pine. Phytopathology 93:691-694.

35. Liu, J.-J., and Ekramoddoullah, A. K. M. 2006. The family 10 of plant pathogenesis-related proteins: Their structure, regulation, and function in response to biotic and abiotic stresses. Physiol. Mol. Plant Pathol. 68:313.

36. Lu, P., Sinclair, R. W., Boult, T. J., and Blake, S. G. 2005. Seedling survival of Pinus strobus and its interspecific hybrids after artificial inoculation of Cronartium ribicola. For. Ecol. Manage. 214:344-357.

37. McDonald, G. I., and Hoff, R. J. 1971. Resistance to Cronartium ribicola in Pinus monticola: Genetic control of needle-spots-only resistance factors. Can. J. For. Res. 1:197-202.

38. Rebertus, A. J., Burns, B. R., and Veblen, T. T. 1991. Stand dynamics of Pinus flexilis-dominated subalpine forests in the Colorado Front Range. J. Veg. Sci. 2:445-458.

39. Samman, S. A. 1982. The white pine blister rust program of Region 6 . Pages 133-183 in: Breeding Insect and Disease Resistant Forest Trees. Proc. Serv. Genet. Workshop. United States Department of Agriculture Forest Service, Eugene, OR

40. Schoettle, A. W. 2004. Ecological roles of five-needle pines in Colorado: Potential consequences of their loss. Pages 124-135 in: Breeding and Genetic Resources of Five-Needle Pines: Growth, Adaptability, and Pest Resistance. Proc. RMRS-P-32. R. A. Sniezko, S. Samman, S. E.
Schlarbaum, and H. B. Kriebel, eds. United States Department of Agriculture, Forest Service, Rocky Mountain Research Station, Fort Collins, CO

41. Schoettle, A. W., Goodrich, B. A., Klutsch, J. G., Burns, K. S., Costello, S., Sniezko, R. A., and Connor, J. 2011. The proactive strategy for sustaining five-needle pine populations: An example of its implementation in the southern Rocky Mountains. Pages 323-334 in: The Future of HighElevation, Five-Needle White Pines in Western North America. Proc. High Five Symp. Missoula, MT. Proc. RMRS-P-63. R. E. Keane, D. F. Tomback, M. P. Murray, and C. M. Smith, eds. United States Department of Agriculture, Forest Service, Rocky Mountain Research Station, Fort Collins, $\mathrm{CO}$

42. Schoettle, A. W., Klutsch, J. G., and Sniezko, R. A. 2012. Integrating regeneration, genetic resistance, and timing of intervention for the longterm sustainability of ecosystems challenged by non-native pests-a novel proactive approach. Pages 112-123 in: Proc. Fourth Int. Workshop Genet. Host-Parasite Interact. For. Disease and Insect Resistance in Forest Trees, Eugene, OR. Gen. Tech. Rep. PSW-GTR-240. R. A. Sniezko, A. D. Yanchuk, J. T. Kliejunas, K. M. Palmieri, J. M. Alexander, S. J. Frankel, tech. coord. United States Department of Agriculture, Forest Service, Pacific Southwest Research Station, Albany, CA.

43. Schoettle, A. W., and Rochelle, S. G. 2000. Morphological variation of Pinus flexilis (Pinaceae), a bird-dispersed pine, across a range of elevations. Am. J. Bot. 87:1797-1806.

44. Schoettle, A. W., and Sniezko, R. A. 2007. Proactive intervention to sustain high-elevation pine ecosystems threatened by white pine blister rust. J. For. Res. 12:327-336.

45. Sniezko, R. A., Kegley, A. J., and Danchok, R. 2008. White pine blister rust resistance in North American, Asian, and European species-results from artificial inoculation trials in Oregon. Ann. For. Res. 51:53-66.

46. Sniezko, R. A., Mahalovich, M. F., Schoettle, A. W., and Vogler, D. R. 2011. Past and current investigations of the genetic resistance to Cronartium ribicola in high-elevation five-needle pines. Pages 246-264 in: The Future of High-Elevation, Five-Needle White Pines in Western North America. Proc. High Five Symp. Missoula, MT. Proc. RMRS-P-63. R. E. Keane, D. F. Tomback, M. P. Murray, and C. M. Smith, eds. United States Department of Agriculture, Forest Service, Rocky Mountain Research Station, Fort Collins, CO

47. Spaulding, P. 1925. A partial explanation of the relative susceptibility of the white pines to the white pine blister rust (Cronartium ribicola Fischer). Phytopathology 15:591-597.

48. Spaulding, P. 1929. White pine blister rust: A comparison of European with North American conditions. U.S. Dep. Agric. Tech. Bull. No. 87.

49. Steinhoff, R. J., and Andresen, J. W. 1971. Geographic variation in Pinus flexilis and Pinus strobiformis and its bearing on their taxonomic status. Silv. Genet. 20:159-167.

50. Stephan, B. R. 1986. The IUFRO experiment on resistance of white pines to blister rust (Cronartium ribicola) in northern Germany. Pages 80-89 in: Proc. 18th IUFRO World Cong. Division II, Vol. I. Ljubljana, Yugoslavia.

51. Sweeney, K., Stone, J., Cook, K., Sniezko, R., Kegley, A., and Schoettle, A. 2012. Are needle reactions in resistance to Cronartium ribicola a Hypersensitivity response? Pages 368-371 in: Proc. Fourth Int. Workshop Genet. Host-Parasite Interact. For. Disease and Insect Resistance in Forest Trees. Eugene, OR. Gen. Tech. Rep. PSW-GTR-240. R. A. Sniezko, A. D. Yanchuk, J. T. Kliejunas, K. M. Palmieri, J. M. Alexander, and S. J. Frankel, tech. coord. United States Department of Agriculture, Forest Service, Pacific Southwest Research Station, Albany, CA.

52. Tomback, D. F., and Achuff, P. 2010. Blister rust and western fores biodiversity: ecology, values and outlook for white pines. For. Pathol. 40:145-417.

53. Vogler, D. R., Delfino-Mix, A., and Schoettle, A. W. 2006. White pine blister rust in high-elevation white pines: Screening for simply-inherited, hypersensitive resistance. Pages 73-82 in: Proc. 53th West. Int. For. Dis. Work Conf. J. C. Guyon, ed. United States Department of Agriculture, Forest Service Intermountain Region, Ogden, UT

54. Yoder, O. C., Valent, B., and Chumley, F. 1986. Genetic nomenclature and practice for plant pathogenic fungi. Phytopathology 76:383-385.

55. Yu, I.-C., Parker, J., and Bent, A. F. 1998. Gene-for-gene disease resistance without the hypersensitive response in Arabidopsis dnd1 mutant. Proc. Natl. Acad. Sci. USA 95:7819-7824. 